\title{
MODIFIED THERAPEUTIC WORK PROGRAM (MTWP) FOR WRIST INJURIES
}

\author{
Surendra Kumar Meena ${ }^{1}$ \\ ${ }^{1}$ Professor \& Principal, \\ Mahatma Gandhi Occupational Therapy \\ College, \\ Mahatma Gandhi University of Medical \\ Sciences \& Technology, \\ Jaipur -302022 \\ Rajasthan, India.
}

\author{
Neha Jain ${ }^{2 *}$ \\ ${ }^{2}$ Assistant Professor, \\ Mahatma Gandhi Occupational Therapy \\ College, \\ Mahatma Gandhi University of Medical \\ Sciences \& Technology, \\ Jaipur -302022, \\ Rajasthan,India.
}

Article DOI: https://doi.org/10.36713/epra0600

\begin{abstract}
Wrist injuries by colles' or fracture of distal radius are the most prominent diagnosis referred to occupational therapy department for work program in India. In this project, a modified therapeutic work program for wrist injuries was evaluated. The objective of the study is to find out whether MTWP addressed to enhance the work skills and its success in the client return to work, level of work satisfaction \& self-performance level post injured wrist.

A different subject prospective, experimental, flexible pre-and-posttest intervention design followed by descriptive analysis with questionnaire has been used for the purpose of this study. The Minnesota Manual Dexterity Test, Hand Dynamometer, Pinch meter, Short Form-36 (version 1) was the main outcome measure. 51 patients with dominant hand injured, shared similar demographic background with post-injured from 8 to 40 weeks with mean age of 16 weeks. Paired ttest showed significance difference $(p<0.05)$ improve in work skill in pre-post MTWP.

94\% clients who completed the program returned to work and switched over to different position and different type of work. 56\% clients return to competitive employment with same work type, work situation, having work satisfaction and 80$100 \%$ work skills in compare to pre MTWP work situation.
\end{abstract}

KEY WORDS: Therapeutic Work Program, Wrist Injuries, Colle's Fracture, Quality Of Life.

\section{INTRODUCTION}

The importance of hand in human culture and functional activities has long been recognized. Wrist is structured to provide a stable base to allow hand to conduct complex motion, and is the major joint responsible for work tasks. In India, wrist injuries are the prominent diagnosis mostly colles' or fracture of distal radius referred to occupational

Therapy department for work program. In this project, a modified therapeutic work program for wrist injuries was evaluated.

Colles' fracture is defined as a linear transverse fracture of the distal radius approximately 20-35 mm proximal to the articular surface with dorsal angulations' of the distal fragment( 1). The unstable fractures are distinctly comminuted often with corresponding avulsions of the ulnar or radial styloid that have the potential to cause compression neuropathies, especially of the median nerve (1). The other complications that have been reported include reflex sympathetic dystrophy and degenerative joint disease (1).

The distal radial fracture is the most frequent of all fractures in trauma surgery (2). One of 6 fractures is of the distal radius (3). Some authors have noted that over $17 \%$ of patients had poor functions one year after injury $(4,5,6)$. The occupational therapist's long-term goal for the patient with distal radial fracture is premorbid functional status of the hand and one of the areas addressed by OT are vocational activities. The 
vocational areas that are addressed (if appropriate) are the patient's present work status; job expectations, especially relating to manual performance; and the patient's willingness to return to his occupation (7).

As the life expectancy continues to increase with increase in industrialization in country like India, the frequency of fractures to the wrist can be expected to increase in years to come. The patients with distal radial fracture are off work from 67days upto 20 weeks $(8,9)$.It is for this reason that post traumatic occupational therapy is critical in restoring function and has a direct influence on the quality of life, as well as duration of sick leave, laborer compensation and therefore is of social economic interest.

In a study on head injured clients Lyons \& Morse (1988) developed a Therapeutic Work Program (TWP) to address client's prevocational \& vocational needs, with prevocational and vocational intervention to facilitate return to work. They reported that $79 \%$ clients who completed the program returned to work (10). As reported by Lyons and Morse, the TWP was originally developed in 1982 at the New England Rehabilitation Hospital by Patricia Harris Minnasian. The program was further developed and refined by Janet Kenig, Maureen Flaherty, and Sharon Engelhardt (10).

The current study is primarily based on the concept of TWP. However it is intended for use on the individual with wrist injury in combination with traditional therapies. Literature search failed to reveal similar studies in Indian context.

Traditionally the individual having wrist injury go through the rehabilitation program without emphasis on the client's ability to return to work. The original Therapeutic Work Program (TWP) has 8 phases (Figure 3), where as in Modified Therapeutic Work Program (MTWP) has 6 phases and it does not include two phases namely; 1.vocational placement 2 . Follow-up.

\section{MATERIAL AND METHODS Design}

Single group pre test post test experimental design followed by descriptive analysis.

A different subject prospective, experimental, flexible design has been used for the purpose of this study. MTWP has 6 phases with treatment plan based on client capabilities, deficits, interest, work history and goals.

Subjects

A total number of 51 subjects having wrist injuries by colles'or fracture distal radius of dominant hand were selected for the study. Mean age was 36 years (range 25 to 55 years) having both male and female. The post injury duration for participation in MTWP is 08 to 40 weeks, mean 16 weeks (Table 1). Period of study from April 09 to Aug 10. Clients were explained the purpose of the study and were requested to participate in the study. Written consent obtained from each participant before study begins.

\section{Inclusion Criteria}

- Self-ambulatory level.

- Manageable social behavior.

- Attention span of 30 minutes in an institutional environment with minimal distraction.

- Ability to establish goals with guidance.

- Ability to follow two steps written verbal or demonstrated direction.

- Unilateral wrist injuries only dominant hand.

\section{Exclusion Criteria-}

- Younger than 18 years

- Lacked self-sufficiency in managing the requirements of daily life (eg. Home-care needed)

- Had psychiatric illness

- Having bone disease (i.e. bone metastasis, osteolysis)

- Had inflammatory joint disease ( i.e. rheumatoid arthritis, gout)

- Previous fracture near the wrist or carpal tunnel syndrome on injured side

- Had reflex sympathetic dystrophy.

\section{Outcome measure used for work skill} assessment

- Minnesota Manual Dexterity Test(MMDT)

- Hand Dynamometer \& Pinch meter

- Short Form-36(version 1) - subjective outcome assessment for functional/ work status. 


\section{MMDT}

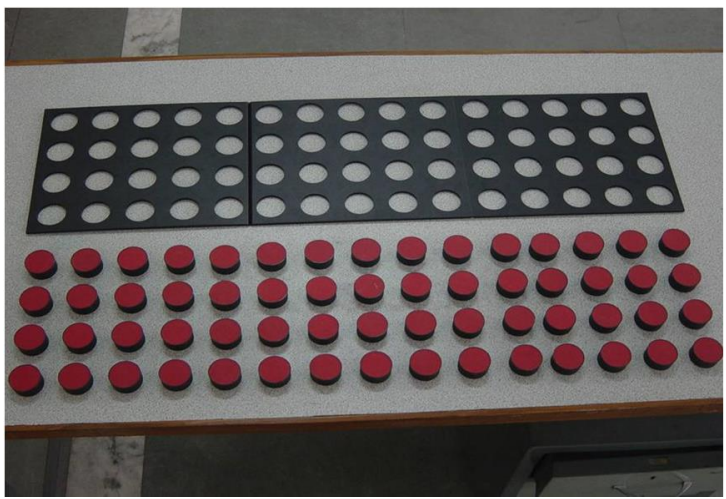

Minnesota Manual Dexterity Test (Figure 1) is a standardized test that measures eye-hand coordination and manual dexterity of the arm and hand for manipulative work. It requires unilateral and bilateral movements while utilizing a broad range of shoulder

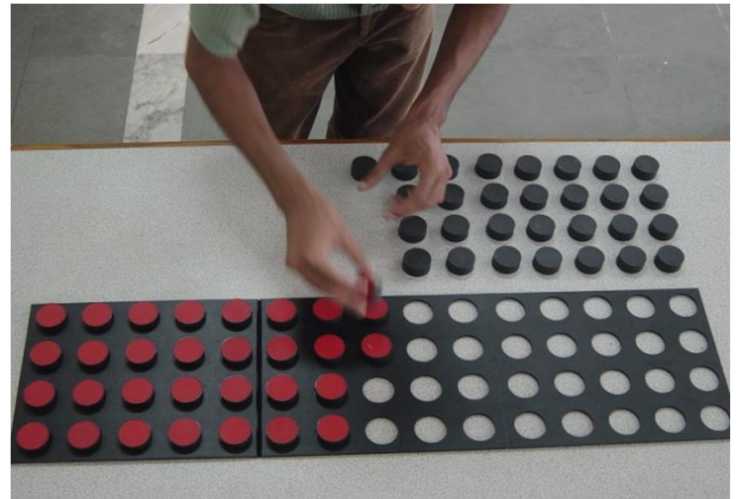

motion. The Minnesota Manual Dexterity Test incorporates two test batteries (Placing test \& Turning test). The tests include 60 two-colored wooden cylinders, plastic board, record forms, norms and manual with test battery instructions.

\section{HAND DYNAMOMETER}

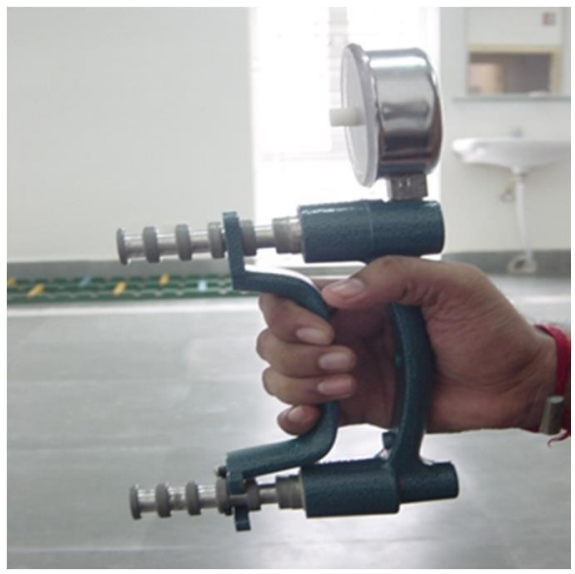

The Hydraulic Jamar grip dynamometer( Figure 2a) with five adjustable handle spacing provides an accurate evaluation of the force of grip .Developed by Bechtol C. (1954) and recommended by professional societies, the Jamer dynamometer has been shown to be a reliable test instrument, provided calibration is maintained and standard positioning of test subject is followed. This dynamometer has five adjustable spacing at 1, 1.5, 2, 2.5 and 3 inches. The client is shown how to grasp the dynamometer and is requested to grasp it with his or her maximal force. The grip test position should be standardized. The forearm should be in neutral rotation and the elbow flexed 90 degree. The shoulder should be adducted .The wrist should be between 0 and 30 degree of extension and 0 and 15 degree of ulnar deviation .The grip can measure at each of the five-handle spacing. The right and left hands are tested alternately and the force of each is recorded. The test is placed at a rate to eliminate fatigue. There are 30 brands new dynamometer available in the market and $80 \%$ met the correlation criterion of + 0.9994. In 1978 and 1983, the ASSH recommended that the second handle position be used and average of 3-trials be recoded. 


\section{PINCH METER}

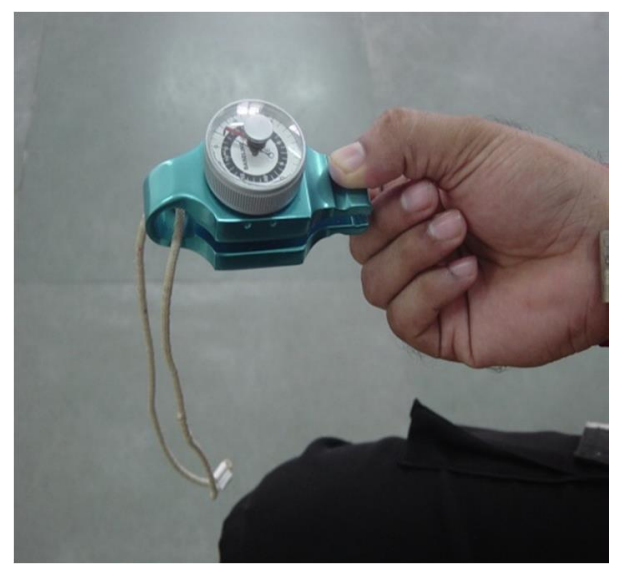

There are three basic type of pinch: (1) Chuck or three finger pinch (Pulp of the thumb to pulp of the index and middle finger) (2) Lateral or key pinch (Prehension of thumb pulp to the lateral aspect of the index middle phalanx) (3) Tip pinch (thumb tip to the tip of the index finger). These 3 types of pinch are usually assessed and can be tested with a pinch meter (Figure 2b). As with grip measurement, the mean of 3 trials is recorded and comparisons are made with the opposite hand. Reliability of pinch meter needs investigation. Hydraulic pinch instruments are more accurate than spring loaded.

\section{SF-36(version 1)}

The SF-36 (John E. Ware, Jr., 1992) is a multipurpose, short-form health survey with only 36 questions. It yields an 8-scale profile of functional health and well-being scores. The four scales Physical Functioning (PF), Role Physical (RP), Role Emotional (RE) \& Social Functioning (SF) correlate most highly with the functional status. It is a generic measure, as opposed to one that targets a specific age, disease, or treatment group. Accordingly, the SF-36 has proven useful in surveys of general and specific populations, comparing the relative burden of diseases, and in differentiating the health benefits produced by a wide range of different treatments.

More recently, the SF-36 was judged to be the most widely evaluated generic patient assessed health outcome measure in a bibliographic study of the growth of "quality of life" measures published in the British Medical Journal (Garratt, Schmidt, Mackintosh, \& Fitzpatrick, 2002).

\section{PROGRAM DESCRIPTION}

The program is designed to help an individual to make a gradual, progressive transition from a medical setting to work placement and community reentry. MTWP has 6 phases. The client functional status and progress were monitored on an ongoing basis, and transition to new phases was determined by the Occupational Therapist and based on the client needs. Not all clients went through each phase or follow the sequence. Client continues with individual occupational therapy throughout their involvement in the MTWP. 


\section{MODIFIED THERAPEUTIC WORK PROGRAMME}

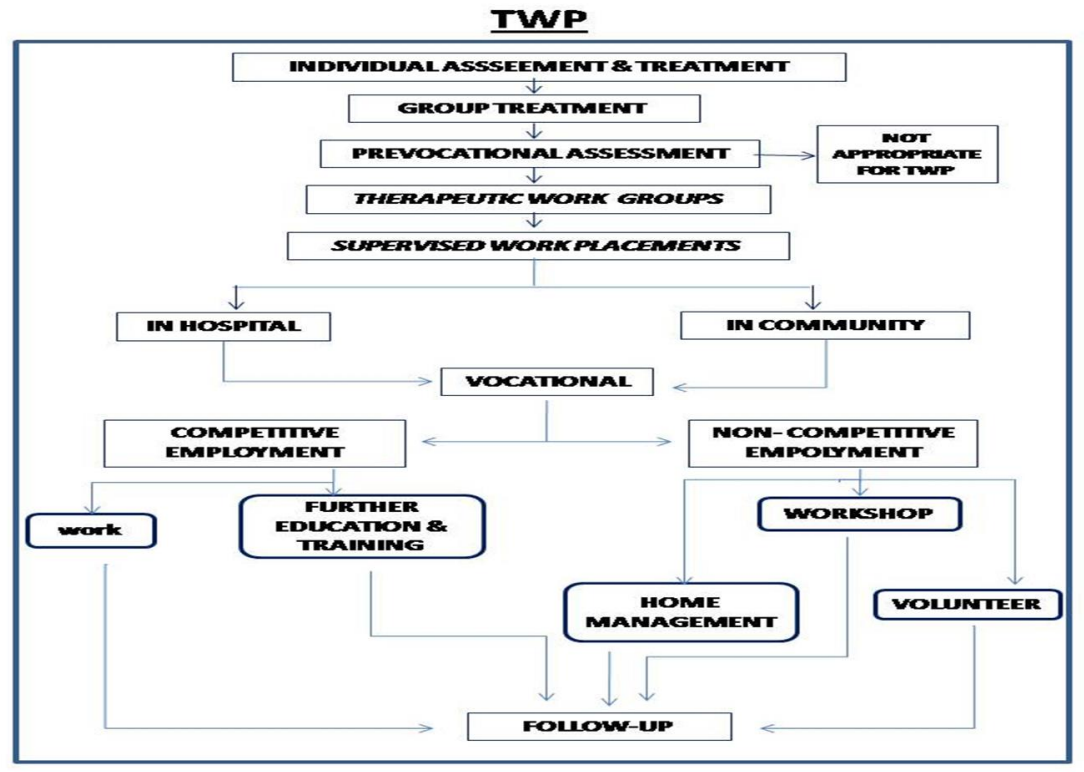

MTWP Six Phases:

\section{Phase 1}

Individual assessment and treatment in occupational therapy department.

Individualized assessment by occupational therapist were obtained from Initial general occupational therapy assessment format, which includes-

-Date of injury, participation in MTWP

-About previous job specification / demand which based on information from Canadian Classification and Dictionary of Occupations.

- Obtaining background information pertinent to work.

-FIM for ADL.

Phase 2

Group treatment.

-In this phase as client progress to higher level of functioning they participate in group treatment.

-Groups are led by occupational therapist.

-Emphasis is on interaction and interpersonal skills.

- Groups are functionally based and focus on area such as functional living skills, debate and effective communication and family education.

Phase 3

Prevocational assessment.

The first two sessions are devoted to a prevocational assessment. These assessments establish a baseline performance level and guides appropriate task selection.
-The outcome measure as mentioned earlier is used here.

-It guides appropriate secretarial task, and assembling task to be chosen as per the need of an individual client. Phase 4

Therapeutic work groups.

-All Initial transition from role of client to the role of worker.

- Client received 5 days per week for 1(One) hour daily for 4 weeks.

-The group structure includes sign an attendance register in and out, a daily routine, involved in variety of assembly tasks (Figure 4) and secretarial task (Figure 5).

-Emphasis is on developing prevocational and work readiness skills, not on training for specific job.

Phase 5

Work placement within the institute.

-Supervised work placements within the institute are available on block printing, appliqué \& computer programming.

-If only client show interest to participate then posted under vocational counselor for further guidance and training.

Phase 6 - Back to previous job or supervised placement in community or further education and training.

-Previously employed client go back to their respective job.

-Supervised placement in community

- Clients engage in further education and training. 
EPRA International Journal of Multidisciplinary Research (IJMR) - Peer Reviewed Journal Volume: 6 | Issue: 10 | October 2020 || Journal DOI: 10.36713/epra2013 || SJIF Impact Factor: 7.032 ||ISI Value: 1.188

\section{RESULT \& DISCUSSION}

Table 1 (Demographic Details of patients participated in MTWP)

\begin{tabular}{|c|c|c|}
\hline Sl. No. & Characteristic & Groups \\
\hline 01 & No. of Subjects & $25-55$ yrs. \\
\hline 02 & Age range & 36 \\
\hline 03 & Mean age & $21 / 30$ \\
\hline 04 & Male/Female & $46 / 05$ \\
\hline 05 & Dominant hand injured Rt./ Lt. & 08 to 40 weeks, mean 16 weeks \\
\hline 06 & Post injury duration &
\end{tabular}

Table - 2

Table 2 (Paired Sample Test)

\begin{tabular}{|l|l|l|l|l|l|}
\hline GROUP & Mean & SD & $\begin{array}{l}\text { SE } \\
\text { Mean }\end{array}$ & T & P \\
\hline Placing Test(PT1-PT2) & 15.38 & 6.34 & 1.31 & 12.78 & 0.01 \\
\hline Turning Test(TT1-TT2) & 13.35 & 6.42 & 1.16 & 11.22 & 0.01 \\
\hline Physical functioning(PF1-PF2) & -24.87 & 6.46 & 1.14 & -18.11 & 0.00 \\
\hline Role limitation to Physical Problems(RP1-RP2) & -18.00 & 7.22 & 1.50 & -12.12 & 0.00 \\
\hline Role limitation to Emotional Problems(RE1-RE2) & -20.96 & 7.11 & 1.35 & -14.66 & 0.00 \\
\hline Social functioning(SF1-SF2) & -22.41 & 10.21 & 1.75 & -12.78 & 0.00 \\
\hline Grip strength Injured side( AFFG1-AFFG2) & -3.60 & 2.48 & 0.44 & -6.92 & 0.01 \\
\hline Grip strength Non-injured side( NAG1-NAG2) & -0.62 & 0.52 & 0.14 & -4.09 & 0.01 \\
\hline Tip to tip pinch injured side( AFFTP1-AFFTP2) & -2.10 & 0.85 & 0.15 & -12.20 & 0.00 \\
\hline Tip to tip pinch non-injured side ( NATP1-NATP2) & -0.72 & 0.66 & 0.12 & -5.20 & 0.00 \\
\hline Key Pinch injured side( AFFKP1-AFFKP2) & -2.66 & 1.22 & 0.18 & -12.36 & 0.00 \\
\hline Key Pinch non-injured( NAKP1-NAKP2 & -0.62 & 0.72 & 0.12 & -4.60 & 0.00 \\
\hline Palmar Pinch injured (AFFPP1-AFFPP2) & -2.40 & 1.02 & 0.18 & -10.80 & 0.00 \\
\hline Palmar Pinch non-injured (NAPP1-NAPP2) & -1.20 & 1.62 & 0.30 & -4.00 & 0.00 \\
\hline
\end{tabular}

Table - 3

Work status comparison of Pre MTWP and Post MTWP Subjects (N - 48)

\begin{tabular}{|c|c|c|}
\hline Work Status & Pre morbid & Post MTWP \\
\hline Competitive employment & 33 & 31 \\
\hline Homemaker & 15 & 14 \\
\hline Trainee & 00 & 01 \\
\hline Unemployed & 00 & 02 \\
\hline
\end{tabular}

Table -4

Work type comparison of Premorbid (N- 48) and Post MTWP (N-46) Subjects

\begin{tabular}{|c|c|c|}
\hline Work Type & Premorbid & Post-MTWP \\
\hline Managerial & 12 & 13 \\
\hline Heavy labor & 03 & 01 \\
\hline Light Labor (Secretarial \& assembling) & 18 & 16 \\
\hline Student & 00 & 01 \\
\hline Home maker & 15 & 14 \\
\hline Others & 00 & 01 \\
\hline
\end{tabular}


Table - 5

Work situation comparison preceding and following Wrist injury (N-46)

\begin{tabular}{|c|c|}
\hline Work Situation & Number of subjects (N -46) \\
\hline Same company / Same position & $39(14) \mathrm{a}$ \\
\hline Same company/ other position & 04 \\
\hline Other company/same work type & 02 \\
\hline Other company/other work type & $01(1) \mathrm{b}$ \\
\hline
\end{tabular}

'a' for home maker and 'b' for student

Table -6

Number of jobs held by subjects since discharge (N-46)

\begin{tabular}{|c|c|}
\hline Number of jobs & Number of Subjects \\
\hline 1 & 37 \\
\hline 2 & 05 \\
\hline $3 \&$ more & 03 \\
\hline NR & 01 \\
\hline
\end{tabular}

'NR' - Not Reported

Table - 7

Subject Work Satisfaction (N - 46)

\begin{tabular}{|l|l|}
\hline Liked their jobs & 32 \\
\hline Job is challenging \& look forward to going to work & 05 \\
\hline Did not enjoy their work & 05 \\
\hline Home makers want to be involved in competitive employment & 03 \\
\hline No response & 01 \\
\hline
\end{tabular}

Table -8

Subjective Work difficulty (N - 46)

Job required more physical demand

Job required high cognitive demand

Easiest job that repetitious, familiar \& required few cognitive \& physical demand

Table -9

Self evaluation of job performance

N-46 (comparing their present work skills with their skills prior to injuries).

\begin{tabular}{|l|l|}
\hline 100 to $80 \%$ of their prior level & 27 \\
\hline 80 to $65 \%$ of their prior level & 05 \\
\hline 65 to $50 \%$ of their prior level & 08 \\
\hline $50 \%$ and below prior level & 06 \\
\hline
\end{tabular}

\section{DISCUSSION}

As table-3 shows, out of 48 clients in premorbid stage, 45 clients were working after participating in the MTWP (31 were competitively employed, 14 primary homemaker) whereas 1 trainee and 2 were unemployed.

The work type comparison (eg. managerial, heavy labor, light labor, home maker) of premorbid and post MTWP subjects (Table-4) shows, the categories of work vary from those prior to the wrist injuries. The clients did work that was different from the work they had done prior to the wrist injuries.

Table- 5 shows, the comparison of present job with former job. Return to the same or a different 
company was related to the length of time of prior employment.

Table- 6 shows, 37 out of 46 subjects had one jobs, 05 had two jobs, 03 had three or more jobs since discharge from MTWP. The majority of respondent, 44 out of 46 were working 40 or more hours per week.

As per job satisfaction level out of 46 subjects; 32 liked their job, 05 did not enjoy their work, 03 home makers want to be involved in competitive employment and 05 subjects feel the job is challenging and look forward to it (Table 7).

Post MTWP in the area of work difficulty, 35 subjects suggest the job that repetitious, familiar, required little cognitive \& physical demand is easy to perform (Table 8). In comparing their present work skills with their skills prior to affection 27 subjects self reported 100 to $80 \%$ of their prior level in job performance (Table 9).

\section{CONCLUSION}

The MTWP addresses the range of needs demonstrated by wrist injuries clients, from traditional therapy to prevocational and vocational intervention. The evaluation of the program indicates that the program was successful with wrist injury working age adult. $94 \%$ clients who completed the program returned to work and switched over to different position and different type of work. $56 \%$ clients return to competitive employment with same work type, work situation, having work satisfaction and $80-100 \%$ work skills in compare to premorbid work.

\section{REFERENCE}

1. Yochum T, Rowe L. Essentials of skeletal radiology. $2^{\text {nd }}$ edition Vol. 1. Maryland: Williams \& Wilkins, 1996; 664-665,756-757.

2. Buterbaugh GA, Palmer AK. Fractures and dislocations of the distal radioulnar joint. Hand Clin. 1988; 4:361-75

3. Golden GN.Treatment and prognosis of Colles' fracture in a North American Community. American Journal of Public Health 1982; 72:605-7.

4. Gartland JJ Jr, Werley CW. Evaluation of healed Colles'fracture. J Bone Joint surgery [AM] 1951; 33-A: 895-907.

5. Bacorn RW, Kurtkze JF. Colles fracture: a study of two thousand cases from the New York State Workmans 'Compensation Board. Journal of Bone Joint surgery [AM] 1953; 35-A: 643-58.

6. Golden GN. Treatment and prognosis of Colles' fracture. Lancet 1963; $i$ : 511-5.

7. Katharine Raymond Morey, Anne Harvey Watson. Team approach to treatment of the post traumatic stiff hand: A case report. Physical Therapy; Vol. 66 No.2, February 1986.
8. Wentzensen A, Leutfink D. External quality assurance exemplified by distal radius fracture pilot projects of legal accident insurance. Z Arztl Fortbild Qualitatssich 1997; 91:484-5.

9. Wittemann M, Jung A, Hornung R, Germann G. Die sog. "kleine Handverletzung" und ihre soziookonomischen Folgen. Chirurg 1994; 65:1004-7.

10. Lyons \& Morse.A Therapeutic Work Program for Head injured clients; AJOT, 1988, 